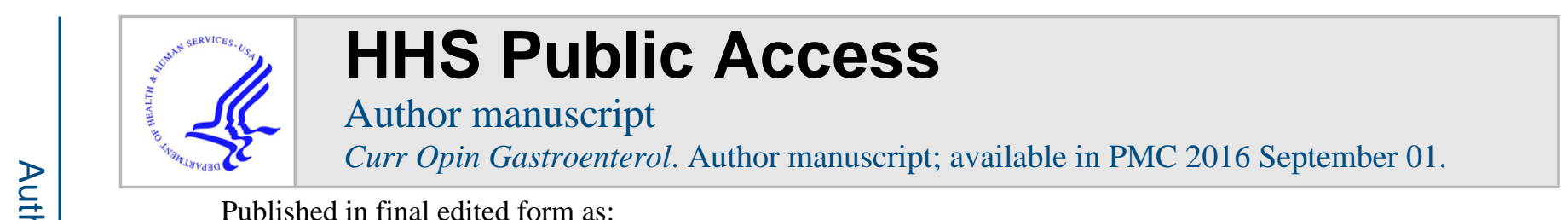

Published in final edited form as:

Curr Opin Gastroenterol. 2015 September ; 31(5): 380-386. doi:10.1097/MOG.0000000000000197.

\title{
PEDIATRIC PANCREATITIS
}

John F. Pohl, MD ${ }^{1}$ and Aliye Uc, MD²

${ }^{1}$ Department of Pediatric Gastroenterology, Primary Children's Hospital, University of Utah School of Medicine, Salt Lake City, Utah

${ }^{2}$ Department of Pediatric Gastroenterology, University of lowa Carver College of Medicine, lowa City, lowa

\begin{abstract}
Purpose of Review-The purpose of this review is to describe recent developments in pediatric pancreatitis and to discuss etiologies and current management.

Recent Findings-Although recent studies have estimated the annual incidence of pediatric acute pancreatitis approaching that of adults, there are no established guidelines about its diagnosis and treatment in children. Genetic and structural/congenital abnormalities are emerging as the primary risk factors for pediatric acute recurrent and chronic pancreatitis. Specifically, chronic pancreatitis is associated with a significant socioeconomic burden in children. Both medical and surgical therapies are proposed for pediatric chronic pancreatitis, but there is little evidence that they are beneficial.
\end{abstract}

Summary-Acute, acute recurrent and chronic pancreatitis create significant health issues in the pediatric population. Medical and surgical therapies exist to potentially treat these conditions, but the pediatric data is limited and the cohorts are small. A multidisciplinary and multicenter approach is necessary to better determine pancreatic disease processes and treatment options in children.

\section{Keywords}

abdominal pain; quality of life; pediatric gastroenterology; genetics

\section{INTRODUCTION}

In children, pancreatitis is categorized as acute pancreatitis (AP), acute recurrent pancreatitis (ARP) and chronic pancreatitis (CP). We have significant gaps in our knowledge of pancreatitis in children. Here we summarize recent advances in the field of pediatric pancreatitis with focus on etiologies, diagnosis and therapy.

Corresponding Author Requests: Aliye Uc, M.D., 2865 JPP Pediatrics, University of Iowa, 200 Hawkins Drive, Iowa City, IA 52242; Tel: (319) 384-6032; Fax:(319) 353-8967; aliye-uc@uiowa.edu.

Conflicts of Interest: Dr. Pohl is on the speaker's bureau for Medical Education Resources, Inc. Dr. Uc served as a Consultant for Abbvie Inc. for exocrine pancreatic function testing. 


\section{ACUTE PANCREATITIS}

Recent studies estimate the incidence of acute pancreatitis (AP) at $~ 1 / 10,000$ children per year [1,2], which approaches incidences reported in adults [3]. This incidence may represent a true rise in pediatric pancreatitis or improved awareness $[1,4,5]$. There are no evidence-based diagnostic guidelines for pancreatic disorders in children. A multicenter

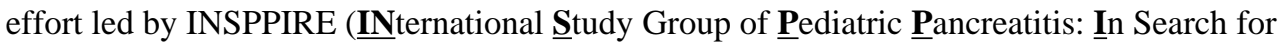
a $\mathrm{Cu} \underline{\mathbf{R E}}$ ) defined AP as requiring 2 of: (1) abdominal pain compatible with AP, (2) serum amylase and/or lipase values $\geq 3$ times upper limits of normal, (3) imaging findings consistent with AP [6, $7^{* *}$ ]. Pediatric AP is associated with significant disease burden. Children with AP are hospitalized for 5-8 days, while infants and toddlers spend approximately 20 days in the hospital [5, 8-10]. An early study estimated the cost of pediatric AP in the US as $\$ 52$ million per year [11]. The cost may be higher than reported due to increased incidence of pediatric AP in recent years, length of stay and higher charges in children hospitalized for AP [12].

\section{Pathophysiology}

The central event in the pathophysiology of AP is acinar cell injury and local tissue damage. The studies in animal models of AP suggest that cytosolic calcium changes, colocalization of zymogens and lysosomes, intraacinar activation of zymogens, nuclear factor- $k b$ activation and inhibition of secretion play a significant role in the pathogenesis of AP. The animal models do not recapitulate the human disease and there is no consensus on a unifying theory. Although intra-acinar activation of trypsinogen has been considered as the main factor leading to cellular injury, it fails to explain all mechanistic events in AP [13].

\section{Etiologies}

In adults, gallstones and excessive alcohol use are the main risk factors of AP. Common causes of AP in children are markedly different compared to the adult population $[4,5,8$ 10, 14-23] (Table 1). Biliary/obstructive factors, medications and systemic diseases are the main causes of AP in the pediatric age group. AP triggered by genetic mutations, metabolic factors, trauma or alcohol is not common in children. AP is idiopathic in $15-30 \%$ of cases.

\section{Diagnosis of AP}

The diagnosis of AP is based on clinical presentation, confirmed by laboratory and/or radiological studies. Abdominal pain and/or irritability are the most common findings of AP in children, followed by epigastric tenderness, nausea and vomiting $[8,10]$. Clinical findings may be subtle in infants and toddlers, thus requiring a high level of suspicion.

Due to its safety profile, non-invasive nature and ability to detect biliary etiologies, the abdominal ultrasound (US) is the imaging modality of choice in children [5, 8]. It must be noted that US has lower sensitivity in visualizing the pancreas compared to computed tomography (CT) [24]. CT imaging of the abdomen can be most helpful in identifying complications of AP (i.e. fluid collections, necrosis, hemorrhage) when performed several days after the initial presentation [25]. 
In general, AP has a mild course in childhood and resolves without complications.

Pancreatic pseudocysts may occur in $\sim 15 \%$ of children with AP and in most cases resolve completely without intervention [2, 8, 9]. A subset of children with AP (6-25\%) may develop severe pancreatic inflammation and necrosis, triggering systemic inflammatory response syndrome (SIRS) and multiorgan failure (shock, renal failure, pulmonary insufficiency). It is not easy to predict the severity of AP at the time of presentation because the scoring systems developed in adults do not typically apply to children [26]. A recent study suggests that serum lipase obtained within 24 hours of presentation may serve as a marker of AP severity in children, with levels over 7 times the upper limit of normal predicting a severe course [27].

\section{Treatment of AP}

Often, the treatment of AP is determined by the etiological factors. Pain control is at the center of AP management, followed by intravenous (IV) hydration and nutrition. In general, narcotic analgesics are preferred drugs for pain management in children [6]. Despite concerns of sphincter of Oddi spasm and further exacerbation of AP with morphine, there is no clinical evidence to support this theory [28].

Fluid resuscitation is critical in the management of AP. However, the volume, rate, timing and components of the IV fluid therapy are not well-established. Studies in adults suggest that early and aggressive fluid resuscitation and pH-buffering capacity of the IV fluid (i.e. lactated ringer) may decrease morbidity and mortality from AP [29-31]. Studies are needed to determine the adequate fluid management in pediatric cases.

Early nutrition (oral, nasogastric or nasojejunal) is safe and may promote more favorable outcomes in AP possibly via maintaining gut barrier function, preventing bacterial translocation and lowering the risk for SIRS [32-35].

Endoscopic or surgical approaches are rarely used in pediatric AP. Endoscopic intervention is indicated within 24 hours for adults with gallstone pancreatitis and cholangitis and within 72 hours if there is high suspicion of common bile duct stone [36, 37]. The optimal timing of cholecystectomy after hospital admission for gallstone pancreatitis may be within 48 hours for mild disease and after 2 weeks for more severe AP [38]. Conservative management is usually sufficient for pancreatic pseudocysts. If needed, pseudocysts may be treated by drainage via radiologic, endoscopic, or surgical techniques [39].

\section{ACUTE RECURRENT AND CHRONIC PANCREATITIS}

According to INSPPIRE, acute recurrent pancreatitis (ARP) is defined as: $\geq 2$ distinct episodes of AP with intervening return to baseline [6]. CP is diagnosed in the presence of: (1) typical abdominal pain plus characteristic imaging findings or; (2) exocrine pancreatic insufficiency (EPI) plus imaging findings or; (3) diabetes plus imaging findings [6]. In children, ARP and CP are overwhelmingly associated with genetic risk factors [40**].

Overall ARP is reported in 15-35\% of children following an initial occurrence of AP [9, 14, $15,41]$ and CP is estimated as $\sim 0.5$ per 100,000 persons per year $[42,43]$. Despite modest 
incidence rates, $\mathrm{ARP}$ and $\mathrm{CP}$ are associated with significant disease burden. Children with $\mathrm{CP}$ experience frequent abdominal pain, emergency room visits and hospitalizations and they undergo numerous endoscopic and surgical procedures [40**].

\section{Etiologies}

The risk factors for ARP and CP are listed in Table 2. Although alcohol and smoking have long been recognized as major risk factors for CP in adults [44-46], they are uncommon in the pediatric age group. A few single center-studies with small cohorts suggest that children with ARP or CP often have mutations in the cationic trypsinogen (PRSS1), cystic fibrosis transmembrane generator (CFTR), serine protease inhibitor Kazal type I (SPINK1), carboxypeptidase 1 (CPA1) genes [15, 47-52], but it is not known whether genetic factors predict a more aggressive disease course in children. A strong association between CPA1 mutations and childhood-onset $\mathrm{CP}$ [52] suggests that genetic risk factors may determine early onset of CP. The genetic variants in the claudin 2 (CLDN2) [53], and chymotrypsin $C$ (CTRC) genes [54], carboxylesterlipase (CEL) and CEL-HYB allele (originating from a crossover between $C E L$ and its neighboring pseudogene, $C E L P)[55,56]$ increase the risk for $\mathrm{CP}$ in adults with idiopathic $\mathrm{CP}$ or already have alcohol and smoking as risk factors. CFTR mutations associated with pancreatitis can occur in the heterozygous or homozygous state [57, 58]. Patients presenting with pancreatitis and homozygous CFTR mutations typically have mild lung manifestations of their cystic fibrosis [58]. Patients who carry $>1$ mild CFTR mutation are pancreatic sufficient and prone to recurrent attacks of pancreatitis [59].

Pancreas divisum is found in $7 \%$ of the general population, but almost half of patients with genetic mutations (primarily CFTR mutations) and pancreatitis [60]. This suggests that pancreas divisum synergizes with genetic mutations to cause ARP and CP.

Autoimmune pancreatitis (AIP) is a poorly defined entity in children and a rare cause of ARP and CP [61]. Possibly most cases of AIP in children are Type 2 [62].

\section{Pathogenesis}

In general $\mathrm{ARP}$ and $\mathrm{CP}$ are considered as disease continuum rather than two separate entities. In children with hereditary pancreatitis, mutations in PRSSI cause activation of trypsinogen as an early event [63]. Premature activation of trypsinogen to trypsin initiates an activation cascade, causing additional trypsinogen activation and conversion of other digestive proenzymes to active enzymes, leading to pancreatic digestion and inflammation [64]. As the ongoing insult to the pancreas continues (genetic mutations, obstructive factors, environmental exposures, etc.), activated inflammatory cells and stellate cells release cytokines and deposit collagen, eventually producing the fibrotic changes typically seen in $\mathrm{CP}$ [23]. The characteristic changes of $\mathrm{CP}$ are progressive fibrotic destruction of the pancreatic exocrine parenchyma leading to exocrine pancreatic insufficiency (EPI), glycemic abnormalities and eventually diabetes. 


\section{Diagnosis of $\mathbf{C P}$}

Chronic or recurrent abdominal pain and impaired quality of life are commonly seen in children with ARP or CP [40, 65**]. Nausea and/or vomiting, anorexia, weight loss may be present. In most cases, serum amylase and lipase are normal or only mildly elevated [66]. Serum transaminases, direct bilirubin, alkaline phosphatase, and gamma-glutamyl transferase levels may be elevated in the setting of a concomitant biliary obstruction [10].

Testing for pancreatitis-associated gene mutations is recommended for all children with ARP or CP (Table 2). Multiple gene mutations or combination of multiple risk factors may be present in the same patient. We recommend sweat chloride in children with ARP or CP if CFTR mutations are present to evaluate for cystic fibrosis.

Long-term consequences of pancreatic inflammation and fibrosis will invariably lead to EPI and diabetes in CP. If EPI has developed, children may have steatorrhea, weight loss and fat-soluble vitamin deficiencies (A, D, E, K). Exocrine pancreatic function can be measured by indirect testing (fecal fat analysis, fecal elastase-1 (FE-1), stool chymotrypsin, ${ }^{13} \mathrm{C}$-mixed triglyceride breath test, serum immunoreactive trypsinogen (IRT), fat soluble vitamin levels) or direct testing (pancreatic stimulation test with Dreiling tube or endoscopic pancreatic function test (ePFT)). Dreiling tube testing is considered as the gold standard to measure the exocrine pancreatic function [67], but this test is not widely performed due to its invasive nature. Additionally, the collection of the duodenal fluid via the endoscope (ePFT) may underestimate pancreatic exocrine secretions and can lead to the diagnosis of EPI erroneously [67]. In recent years, FE-1 has proven to be a relatively easy and accurate method of detecting EPI. Although the sensitivity of FE1 to diagnose moderate and severe EPI is excellent, it cannot be used for the diagnosis of mild cases [68]. FE-1 may also be falsely low in patients with watery diarrhea. Pancreatic endocrine insufficiency (defined as "type 3 c diabetes mellitus") is a late complication of CP characterized as impaired beta cell function and relatively minor to no insulin resistance. Testing for Hemoglobin A1c and fasting blood glucose is recommended to screen for type $3 c$ diabetes mellitus $[69,70]$. Impairment in either fasting glucose or HbAlc should be further evaluated by a standard oral glucose tolerance test. There is a lifetime risk for pancreatic adenocarcinoma in patients with CP (4\%) [71], and this risk is much higher in patients with HP ( 40\%) [72].

As pancreatic destruction progresses, lesions become easier to detect with imaging techniques including abdominal US, CT, magnetic resonance cholangiopancreatography (MRCP), endoscopic ultrasonography (EUS) and endoscopic retrograde cholangiopancreatography (ERCP). Ductal calculi, dilated side branches, parenchymal calcifications, irreversible ductal obstruction or stricture/dilatation/irregularities are common imaging findings of $\mathrm{CP} . \mathrm{MRCP}$ is the test of choice in children because it is non-invasive, accurate, and does not have associated radiation exposure. Intravenous secretin may enhance the diagnostic accuracy of MRCP [73]. ERCP is mainly reserved for CP complications requiring interventions [74]. 


\section{Treatment of CP}

Pain control is the mainstay of $\mathrm{CP}$ management. We recommend avoiding long-term opioid therapy, but rather manage the neuropathic pain of $\mathrm{CP}$ with tricyclic antidepressants, gabapentin, or pregabalin $[62,75,76]$.

Pancreatic enzymes are commonly prescribed in $\mathrm{CP}$ to reduce the feedback loop in the duodenum by reducing cholecystokinin release and inhibiting pancreatic exocrine activation, however their efficacy for pain control is debated [77]. Antioxidants are proposed for the treatment of chronic pain in CP, but their benefit is not established [78]. Studies are needed to evaluate the utility of these therapies in pediatric ARP or CP.

Endoscopic therapy may be useful if there is an identifiable stricture and pancreatic duct obstruction $[79,80]$. Children with ARP or CP may experience significant benefit following therapeutic ERCP [81, 82*].

Surgery may be indicated for CP in the presence of debilitating chronic pain. Surgical techniques include drainage operations that aim to decompress dilated ducts or resections of strictures/removal of pancreatic stones. In general, decompressive operations (i.e. Puestow operation) are preferred in the pediatric age group [83]. Total pancreatectomy with islet cell autotransplantation (TP/IAT) is being proposed as a treatment for CP and recent studies report a more favorable outcome in children compared to adults [84-93**]. Even though single center experiences are encouraging, TP/IAT is an irreversible choice, which is associated with a significant risk of life-long diabetes after the procedure.

\section{CONCLUSIONS}

Pancreatitis is associated with significant disease burden in childhood. Although we are just beginning to understand the etiologies and socioeconomic burden of pancreatitis in children, many questions still remain. We have yet to determine the natural history of pediatric pancreatitis, identify risk factors for initiation and sequelae of $\mathrm{CP}$ and develop therapies to improve clinical outcomes. Because pancreatitis is not common in pediatrics, prospective multicenter longitudinal studies are crucial to address the fundamental gaps in knowledge.

\section{Acknowledgments}

None

Funding: This work is supported by funding through NIH DK096327 (AU), DK097820 (AU)

\section{REFERENCES AND RECOMMENDED READING}

Papers of particular interest, published within the annual period of review, have been highlighted as:

* of special interest

** of outstanding interest 
1. Morinville VD, Barmada MM, Lowe ME. Increasing incidence of acute pancreatitis at an American pediatric tertiary care center: is greater awareness among physicians responsible? Pancreas. 2010; 39:5-8. [PubMed: 19752770]

2. Nydegger A, Heine RG, Ranuh R, et al. Changing incidence of acute pancreatitis: 10-year experience at the Royal Children's Hospital, Melbourne. J Gastroenterol Hepatol. 2007; 22:13131316. [PubMed: 17489962]

3. Corfield AP, Cooper MJ, Williamson RC. Acute pancreatitis: a lethal disease of increasing incidence. Gut. 1985; 26:724-729. [PubMed: 4018637]

4. Bai HX, Lowe ME, Husain SZ. What have we learned about acute pancreatitis in children? J Pediatr Gastroenterol Nutr. 2011; 52:262-270. [PubMed: 21336157]

5. Park A, Latif SU, Shah AU, et al. Changing referral trends of acute pancreatitis in children: A 12year single-center analysis. J Pediatr Gastroenterol Nutr. 2009; 49:316-322. [PubMed: 19503003]

6. Morinville VD, Husain SZ, Bai H, et al. Definitions of pediatric pancreatitis and survey of present clinical practices. J Pediatr Gastroenterol Nutr. 2012; 55:261-265. [PubMed: 22357117]

7**. Morinville VD, Lowe ME, Ahuja M, et al. Design and Implementation of Insppire (International Study Group of Pediatric Pancreatitis: in Search for a Cure). J Pediatr Gastroenterol Nutr. 2014 This article describes the development of a multi-center, collaborative effort to study pediatric pancreatitis.

8. Kandula L, Lowe ME. Etiology and outcome of acute pancreatitis in infants and toddlers. J Pediatr. 2008; 152:106-110. 110. [PubMed: 18154910]

9. Werlin SL, Kugathasan S, Frautschy BC. Pancreatitis in children. J Pediatr Gastroenterol Nutr. 2003; 37:591-595. [PubMed: 14581803]

10. Park AJ, Latif SU, Ahmad MU, et al. A comparison of presentation and management trends in acute pancreatitis between infants/toddlers and older children. J Pediatr Gastroenterol Nutr. 2010; 51:167-170. [PubMed: 20479687]

11. Fagenholz PJ, Fernandez-del CC, Harris NS, et al. Direct medical costs of acute pancreatitis hospitalizations in the United States. Pancreas. 2007; 35:302-307. [PubMed: 18090234]

12. Pant C, Deshpande A, Olyaee M, et al. Epidemiology of acute pancreatitis in hospitalized children in the United States from 2000-2009. PLoS One. 2014; 9:e95552. [PubMed: 24805879]

13. Saluja AK, Dudeja V. Relevance of animal models of pancreatic cancer and pancreatitis to human disease. Gastroenterology. 2013; 144:1194-1198. [PubMed: 23622128]

14. Lopez MJ. The changing incidence of acute pancreatitis in children: a single-institution perspective. J Pediatr. 2002; 140:622-624. [PubMed: 12032533]

15. Sanchez-Ramirez CA, Larrosa-Haro A, Flores-Martinez S, et al. Acute and recurrent pancreatitis in children: etiological factors. Acta Paediatr. 2007; 96:534-537. [PubMed: 17306005]

16. Fujishiro J, Masumoto K, Urita Y, et al. Pancreatic complications in pediatric choledochal cysts. J Pediatr Surg. 2013; 48:1897-1902. [PubMed: 24074664]

17. Nitsche C, Maertin S, Scheiber J, et al. Drug-induced pancreatitis. Curr Gastroenterol Rep. 2012; 14:131-138. [PubMed: 22314811]

18. Trivedi CD, Pitchumoni CS. Drug-induced pancreatitis: an update. J Clin Gastroenterol. 2005; 39:709-716. [PubMed: 16082282]

19. Spanier BW, Tuynman HA, van der Hulst RW, et al. Acute pancreatitis and concomitant use of pancreatitis-associated drugs. Am J Gastroenterol. 2011; 106:2183-2188. [PubMed: 21912439]

20. Berney T, Belli D, Bugmann P, et al. Influence of severe underlying pathology and hypovolemic shock on the development of acute pancreatitis in children. J Pediatr Surg. 1996; 31:1256-1261. [PubMed: 8887096]

21. Bai HX, Ma MH, Orabi AI, et al. Novel characterization of drug-associated pancreatitis in children. J Pediatr Gastroenterol Nutr. 2011; 53:423-428. [PubMed: 21681111]

22. Lowe ME, Greer JB. Pancreatitis in children and adolescents. Curr Gastroenterol Rep. 2008; 10:128-135. [PubMed: 18462598]

23. Lowe ME. Pancreatitis in childhood. Curr Gastroenterol Rep. 2004; 6:240-246. [PubMed: 15128492] 
24. Silverstein W, Isikoff MB, Hill MC, Barkin J. Diagnostic imaging of acute pancreatitis: prospective study using CT and sonography. AJR Am J Roentgenol. 1981; 137:497-502. [PubMed: 7025598]

25. Sharma V, Rana SS, Sharma RK, et al. Clinical outcomes and prognostic significance of early vs. late computed tomography in acute pancreatitis. Gastroenterology report. 2014

26. Uc A. Predicting the severity of pediatric acute pancreatitis: are we there yet? J Pediatr Gastroenterol Nutr. 2013; 56:584-585. [PubMed: 23535763]

27. Coffey MJ, Nightingale S, Ooi CY. Serum lipase as an early predictor of severity in pediatric acute pancreatitis. J Pediatr Gastroenterol Nutr. 2013; 56:602-608. [PubMed: 23403441]

28. Thompson DR. Narcotic analgesic effects on the sphincter of Oddi: a review of the data and therapeutic implications in treating pancreatitis. Am J Gastroenterol. 2001; 96:1266-1272. [PubMed: 11316181]

29. Gardner TB, Vege SS, Chari ST, et al. Faster rate of initial fluid resuscitation in severe acute pancreatitis diminishes in-hospital mortality. Pancreatology. 2009; 9:770-776. [PubMed: 20110744]

30. Wu BU, Hwang JQ, Gardner TH, et al. Lactated Ringer's solution reduces systemic inflammation compared with saline in patients with acute pancreatitis. Clin Gastroenterol Hepatol. 2011; 9:710 717. e711. [PubMed: 21645639]

31. Warndorf MG, Kurtzman JT, Bartel MJ, et al. Early fluid resuscitation reduces morbidity among patients with acute pancreatitis. Clin Gastroenterol Hepatol. 2011; 9:705-709. [PubMed: 21554987]

32. Kumar S, Gariepy CE. Nutrition and acute pancreatitis: review of the literature and pediatric perspectives. Curr Gastroenterol Rep. 2013; 15:338. [PubMed: 23852570]

33. Eckerwall GE, Tingstedt BB, Bergenzaun PE, Andersson RG. Immediate oral feeding in patients with mild acute pancreatitis is safe and may accelerate recovery--a randomized clinical study. Clin Nutr. 2007; 26:758-763. [PubMed: 17719703]

34. Eatock FC, Chong P, Menezes N, et al. A randomized study of early nasogastric versus nasojejunal feeding in severe acute pancreatitis. Am J Gastroenterol. 2005; 100:432-439. [PubMed: 15667504]

35. Moraes JM, Felga GE, Chebli LA, et al. A full solid diet as the initial meal in mild acute pancreatitis is safe and result in a shorter length of hospitalization: results from a prospective, randomized, controlled, double-blind clinical trial. J Clin Gastroenterol. 2010; 44:517-522. [PubMed: 20054282]

36. American Gastroenterological Association Institute on "Management of Acute Pancreatits" Clinical P Economics C Board AGAIG. AGA Institute medical position statement on acute pancreatitis. Gastroenterology. 2007; 132:2019-2021. [PubMed: 17484893]

37. Forsmark CE, Baillie J, et al. Practice AGAIC. AGA Institute technical review on acute pancreatitis. Gastroenterology. 2007; 132:2022-2044. [PubMed: 17484894]

38. Wilson CT, de Moya MA. Cholecystectomy for acute gallstone pancreatitis: early vs delayed approach. Scand J Surg. 2010; 99:81-85. [PubMed: 20679042]

39. Varadarajulu S, Bang JY, Sutton BS, et al. Equal efficacy of endoscopic and surgical cystogastrostomy for pancreatic pseudocyst drainage in a randomized trial. Gastroenterology. 2013; 145:583-590. e581. [PubMed: 23732774]

40**. Schwarzenberg SJ, Bellin M, Husain SZ, et al. Pediatric Chronic Pancreatitis Is Associated with Genetic Risk Factors and Substantial Disease Burden. J Pediatr. 2014 This is the first and largest multi-center cohort describing disease characteristics in children with chronic pancreatitis; most notably the genetic factors are the most common risk factors whereas environmental factors (i.e. alcohol, smoking) are practically non-existent, with high disease burden in pediatric CP.

41. Pezzilli R, Morselli-Labate AM, Castellano E, et al. Acute pancreatitis in children. An Italian multicentre study. Dig Liver Dis. 2002; 34:343-348. [PubMed: 12118952]

42. Yadav D, Timmons L, Benson JT, et al. Incidence, prevalence, and survival of chronic pancreatitis: a population-based study. Am J Gastroenterol. 2011; 106:2192-2199. [PubMed: 21946280] 
43. Spanier B, Bruno MJ, Dijkgraaf MG. Incidence and mortality of acute and chronic pancreatitis in the Netherlands: a nationwide record-linked cohort study for the years 1995-2005. World J Gastroenterol. 2013; 19:3018-3026. [PubMed: 23716981]

44. Mayerle J, Hoffmeister A, Werner J, et al. Chronic pancreatitis--definition, etiology, investigation and treatment. Dtsch Arztebl Int. 2013; 110:387-393. [PubMed: 23826027]

45. Coté GA, Yadav D, Slivka A, et al. Alcohol and smoking as risk factors in an epidemiology study of patients with chronic pancreatitis. Clin Gastroenterol Hepatol. 2011; 9:266-273. quiz e227. [PubMed: 21029787]

46. Beer S, Zhou J, Szabo A, et al. Comprehensive functional analysis of chymotrypsin C (CTRC) variants reveals distinct loss-of-function mechanisms associated with pancreatitis risk. Gut. 2013; 62:1616-1624. [PubMed: 22942235]

47. Schnur A, Beer S, Witt H, et al. Functional effects of 13 rare PRSS1 variants presumed to cause chronic pancreatitis. Gut. 2014; 63:337-343. [PubMed: 23455445]

48. Lucidi V, Alghisi F, Dall'Oglio L, et al. The etiology of acute recurrent pancreatitis in children: a challenge for pediatricians. Pancreas. 2011; 40:517-521. [PubMed: 21499205]

49. Sobczynska-Tomaszewska A, Bak D, Oralewska B, et al. Analysis of CFTR, SPINK1, PRSS1 and AAT mutations in children with acute or chronic pancreatitis. J Pediatr Gastroenterol Nutr. 2006; 43:299-306. [PubMed: 16954950]

50. van Geenen EJ, Smits MM, Schreuder TC, et al. Smoking is related to pancreatic fibrosis in humans. Am J Gastroenterol. 2011; 106:1161-1166. quiz 1167. [PubMed: 21577244]

51. Witt H. Gene mutations in children with chronic pancreatitis. Pancreatology. 2001; 1:432-438. [PubMed: 12120220]

52. Witt H, Beer S, Rosendahl J, et al. Variants in CPA1 are strongly associated with early onset chronic pancreatitis. Nat Genet. 2013; 45:1216-1220. [PubMed: 23955596]

53. Derikx MH, Kovacs P, Scholz M, et al. Polymorphisms at PRSS1-PRSS2 and CLDN2-MORC4 loci associate with alcoholic and non-alcoholic chronic pancreatitis in a European replication study. Gut. 2014

54. LaRusch J, Lozano-Leon A, Stello K, et al. The Common Chymotrypsinogen C (CTRC) Variant G60G (C. 180T) Increases Risk of Chronic Pancreatitis But Not Recurrent Acute Pancreatitis in a North American Population. Clinical and translational gastroenterology. 2015; 6:e68. [PubMed: 25569187]

55. Fjeld K, Weiss FU, Lasher D, et al. A recombined allele of the lipase gene CEL and its pseudogene CELP confers susceptibility to chronic pancreatitis. Nat Genet. 2015

56. Ragvin A, Fjeld K, Weiss FU, et al. The number of tandem repeats in the carboxyl-ester lipase (CEL) gene as a risk factor in alcoholic and idiopathic chronic pancreatitis. Pancreatology. 2013; 13:29-32. [PubMed: 23395566]

57. Sharer N, Schwarz M, Malone G, et al. Mutations of the cystic fibrosis gene in patients with chronic pancreatitis. N Engl J Med. 1998; 339:645-652. [PubMed: 9725921]

58. Cohn JA, Friedman KJ, Noone PG, et al. Relation between mutations of the cystic fibrosis gene and idiopathic pancreatitis. N Engl J Med. 1998; 339:653-658. [PubMed: 9725922]

59. Ooi CY, Dorfman R, Cipolli M, et al. Type of CFTR mutation determines risk of pancreatitis in patients with cystic fibrosis. Gastroenterology. 2011; 140:153-161. [PubMed: 20923678]

60. Bertin C, Pelletier AL, Vullierme MP, et al. Pancreas divisum is not a cause of pancreatitis by itself but acts as a partner of genetic mutations. Am J Gastroenterol. 2012; 107:311-317. [PubMed: 22158025]

61. Friedlander J, Quiros JA, Morgan T, et al. Diagnosis of autoimmune pancreatitis vs neoplasms in children with pancreatic mass and biliary obstruction. Clin Gastroenterol Hepatol. 2012; 10:10511055. e1051. [PubMed: 22732272]

62. Kamisawa T, Chari ST, Lerch MM, et al. Recent advances in autoimmune pancreatitis: type 1 and type 2. Gut. 2013; 62:1373-1380. [PubMed: 23749606]

63. Whitcomb DC, Gorry MC, Preston RA, et al. Hereditary pancreatitis is caused by a mutation in the cationic trypsinogen gene. Nat Genet. 1996; 14:141-145. [PubMed: 8841182]

64. Kandula L, Whitcomb DC, Lowe ME. Genetic issues in pediatric pancreatitis. Curr Gastroenterol Rep. 2006; 8:248-253. [PubMed: 16764792] 
65. Pohl JF, Limbers CA, Kay M, et al. Health-Related Quality of Life in Pediatric Patients with LongStanding Pancreatitis. J Pediatr Gastroenterol Nutr. 2011

66. Steer ML, Waxman I, Freedman S. Chronic pancreatitis. N Engl J Med. 1995; 332:1482-1490. [PubMed: 7739686]

67. Schibli S, Corey M, Gaskin KJ, et al. Towards the ideal quantitative pancreatic function test: analysis of test variables that influence validity. Clin Gastroenterol Hepatol. 2006; 4:90-97. [PubMed: 16431310]

68. Daftary A, Acton J, Heubi J, Amin R. Fecal elastase-1: utility in pancreatic function in cystic fibrosis. J Cyst Fibros. 2006; 5:71-76. [PubMed: 16603421]

69. Ewald N, Hardt PD. Diagnosis and treatment of diabetes mellitus in chronic pancreatitis. World J Gastroenterol. 2013; 19:7276-7281. [PubMed: 24259958]

70. Rickels MR, Bellin M, Toledo FG, et al. Detection, evaluation and treatment of diabetes mellitus in chronic pancreatitis: recommendations from PancreasFest 2012. Pancreatology. 2013; 13:336342. [PubMed: 23890130]

71. Lowenfels AB, Maisonneuve P, Cavallini G, et al. Pancreatitis and the risk of pancreatic cancer. International Pancreatitis Study Group. N Engl J Med. 1993; 328:1433-1437. [PubMed: 8479461]

72. Lowenfels AB, Maisonneuve P, DiMagno EP, et al. Hereditary pancreatitis and the risk of pancreatic cancer. International Hereditary Pancreatitis Study Group. J Natl Cancer Inst. 1997; 89:442-446. [PubMed: 9091646]

73. Manfredi R, Lucidi V, Gui B, et al. Idiopathic chronic pancreatitis in children: MR cholangiopancreatography after secretin administration. Radiology. 2002; 224:675-682. [PubMed: 12202699]

74. Issa H, Al-Haddad A, Al-Salem AH. Diagnostic and therapeutic ERCP in the pediatric age group. Pediatr Surg Int. 2007; 23:111-116. [PubMed: 17149628]

75. Butkovic D, Toljan S, Mihovilovic-Novak B. Experience with gabapentin for neuropathic pain in adolescents: report of five cases. Paediatric anaesthesia. 2006; 16:325-329. [PubMed: 16490100]

76. Moore RA, Wiffen PJ, Derry S, McQuay HJ. Gabapentin for chronic neuropathic pain and fibromyalgia in adults. Cochrane Database Syst Rev. 2011:CD007938. [PubMed: 21412914]

77. Shafiq N, Rana S, Bhasin D, et al. Pancreatic enzymes for chronic pancreatitis. Cochrane Database Syst Rev. 2009:CD006302. [PubMed: 19821359]

78. Ahmed Ali U, Jens S, Busch OR, et al. Antioxidants for pain in chronic pancreatitis. Cochrane Database Syst Rev. 2014; 8:CD008945. [PubMed: 25144441]

79. Cremer M, Deviere J, Delhaye M, et al. Stenting in severe chronic pancreatitis: results of mediumterm follow-up in seventy-six patients. Endoscopy. 1991; 23:171-176. [PubMed: 1860448]

80. Ponchon T, Bory RM, Hedelius F, et al. Endoscopic stenting for pain relief in chronic pancreatitis: results of a standardized protocol. Gastrointest Endosc. 1995; 42:452-456. [PubMed: 8566637]

81. Bhasin DK, Rana SS, Sidhu RS, et al. Clinical presentation and outcome of endoscopic therapy in patients with symptomatic chronic pancreatitis associated with pancreas divisum. JOP. 2013; 14:50-56. [PubMed: 23306335]

82*. Agarwal J, Nageshwar Reddy D, Talukdar R, et al. ERCP in the management of pancreatic diseases in children. Gastrointest Endosc. 2014; 79:271-278. This study reports beneficial effects of therapeutic ERCP in children with AP, ARP or CP. [PubMed: 24060520]

83. Andersen DK, Frey CF. The evolution of the surgical treatment of chronic pancreatitis. Ann Surg. 2010; 251:18-32. [PubMed: 20009754]

84. Bellin MD, Beilman GJ, Dunn TB, et al. Islet autotransplantation to preserve beta cell mass in selected patients with chronic pancreatitis and diabetes mellitus undergoing total pancreatectomy. Pancreas. 2013; 42:317-321. [PubMed: 23146918]

85. Bellin MD, Blondet JJ, Beilman GJ, et al. Predicting islet yield in pediatric patients undergoing pancreatectomy and autoislet transplantation for chronic pancreatitis. Pediatr Diabetes. 2010; 11:227-234. [PubMed: 19708905]

86. Bellin MD, Carlson AM, Kobayashi T, et al. Outcome after pancreatectomy and islet autotransplantation in a pediatric population. J Pediatr Gastroenterol Nutr. 2008; 47:37-44. [PubMed: 18607267] 
87. Bellin MD, DERS, Robertson RP. Pancreatectomy and autologous islet transplantation for painful chronic pancreatitis: indications and outcomes. Hosp Pract (1995). 2012; 40:80-87. [PubMed: 23086097]

88**. Bellin MD, Freeman ML, Gelrud A, et al. Total pancreatectomy and islet autotransplantation in chronic pancreatitis: recommendations from PancreasFest. Pancreatology. 2014; 14:27-35. Recommendations for evaluation and treatment of candidate patients for total pancreatectomy and islet auto transplantation. [PubMed: 24555976]

89. Bellin MD, Freeman ML, Schwarzenberg SJ, et al. Quality of life improves for pediatric patients after total pancreatectomy and islet autotransplant for chronic pancreatitis. Clin Gastroenterol Hepatol. 2011; 9:793-799. [PubMed: 21683160]

90. Bellin MD, Gelrud A, Arreaza-Rubin G, et al. Total Pancreatectomy With Islet Autotransplantation: Summary of an NIDDK Workshop. Ann Surg. 2015; 261:21-29. [PubMed: 25599324]

91. Bellin MD, Sutherland DE. Pediatric islet autotransplantation: indication, technique, and outcome. Curr Diab Rep. 2010; 10:326-331. [PubMed: 20680524]

92. Chinnakotla S, Bellin MD, Schwarzenberg SJ, et al. Total pancreatectomy and islet autotransplantation in children for chronic pancreatitis: indication, surgical techniques, postoperative management, and long-term outcomes. Ann Surg. 2014; 260:56-64. [PubMed: 24509206]

93**. Chinnakotla S, Radosevich DM, Dunn TB, et al. Long-term outcomes of total pancreatectomy and islet auto transplantation for hereditary/genetic pancreatitis. J Am Coll Surg. 2014; 218:530 543. A single center study reviewing the long-term outcome in children who underwent total pancreatectomy and islet auto transplantation. [PubMed: 24655839] 


\section{KEY POINTS}

- There are significant gaps in our understanding of pediatric pancreatitis.

- Acute pancreatitis is an emerging disease in childhood with annual incidence similar to those found in adults.

- Children with acute recurrent and chronic pancreatitis have a high prevalence of genetic risk factors with few confounding environmental factors, thus distinguishing it from adult pancreatitis populations.

- Children with chronic pancreatitis have a significant burden of disease, including pain, school absences, and hospitalizations.

- Prospective multicenter studies are crucial to address the fundamental gaps in knowledge. 


\title{
Table 1
}

Risk Factors for Pediatric Acute Pancreatitis [4, 5, 8-10, 14-23]

\author{
Biliary/obstructive factors (10-30\%) \\ Gallstones \\ Biliary sludge \\ Pancreas divisum \\ Choledochal cyst \\ Sphincter of Oddi dysfunction \\ Annular pancreas \\ Medications (5-25\%) \\ Valproic acid \\ 6-mercaptopurine/azathioprine \\ L-asparaginase \\ Mesalamine \\ Trimethoprim/sulfamethoxazole \\ Furosemide \\ Tacrolimus \\ Steroids \\ Systemic diseases (10-50\%) \\ Sepsis \\ Shock \\ Inflammatory bowel disease \\ Hemolytic-uremic syndrome \\ Trauma (10-20\%) \\ Viral infection (8-10\%) \\ Metabolic diseases (5-10\%) \\ Diabetic ketoacidosis \\ Hypertriglyceridemia \\ Inborn errors of metabolism \\ Hypercalcemia \\ Idiopathic (15-30\%) \\ Others (ERCP, genetic factors, alcohol $<10 \%$ )
}


Table 2

Risk Factors for Pediatric Acute Recurrent and Chronic Pancreatitis [15, 40, 44-46, 47-62]

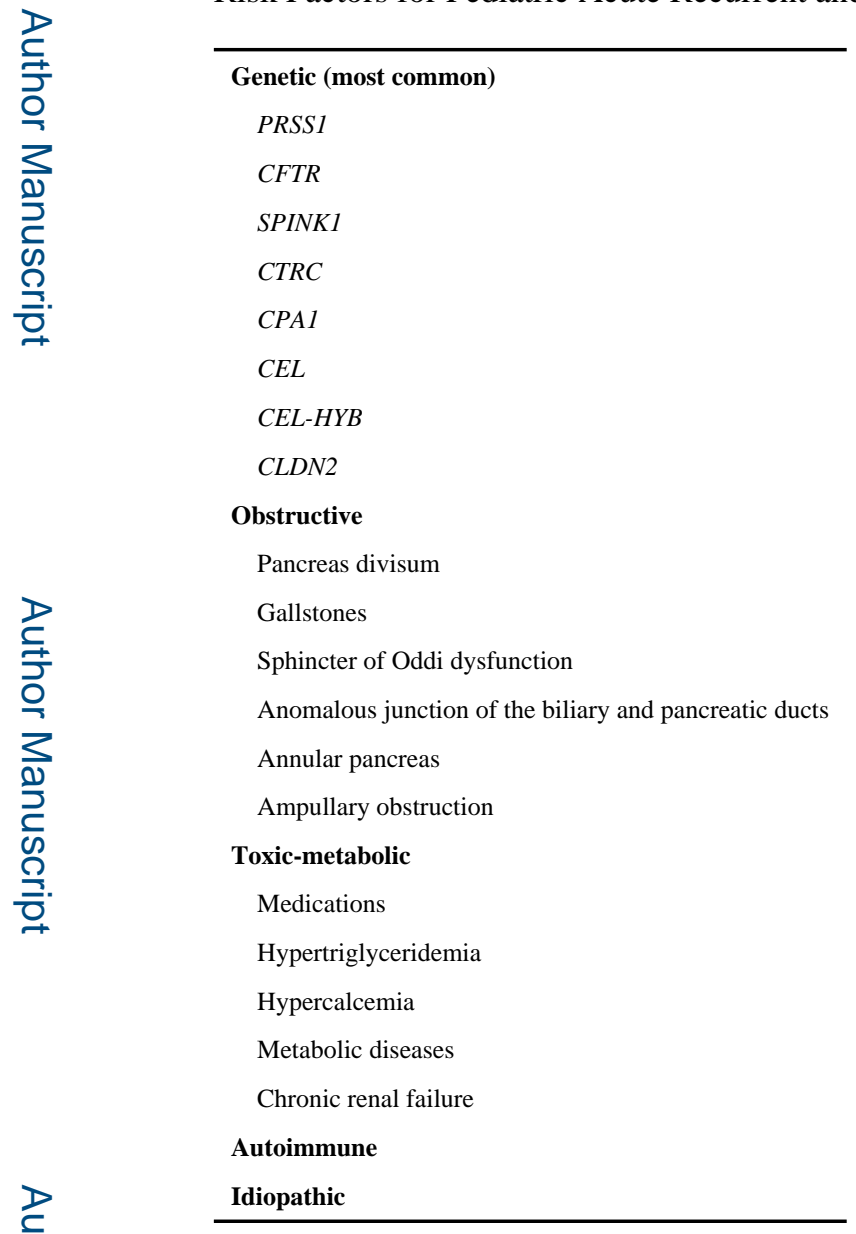

